\title{
DIATHERMY: USES AND ABUSES
}

\author{
By G. S. SCHERMBRUCKER, M.C.S.P. (London), M.E.
}

\begin{abstract}
T $\mathrm{N}$ this short paper I would like to discuss, very briefly, the subject of Diathermy. It is a useful physiotherapeutic agent which, however, lends itself to considerable abuse. The improvement in construction has been most marked of recent years, so much so, in fact, that the administering of this treatment has become practically fool-proof, and very nearly danger-proof. For this reason, I think it wise that the qualified physiotherapist should use all means at his disposal to publicise the real value of deep therapeutic heat, and to condemn its misuse in
\end{abstract} conditions which are not amenable to it.

Diathermy is "Deep Heat" as Cumberbach has defined it and, indeed as its name implies. Whether this deep heat is obtained by the use of a longwave output, or a short wave unit, of whatever frequency, does not appear to have any known physiological significance. It is well-known, and generally accepted, that the heating of tissues by shortwave, is more intense and more rapidly obtained than by the use of a long-wave diathermy current, and for that reason the latter is rarely, if ever, employed in modern practice. The danger of blistering, however, is infinitely greater with the long-wave method, as the "Edge Effect" (as described by Cumberbach) is completely eliminated, and the technical application of short-wave is very much simpler. Is this, perhaps, why it is so often abused? Its administration is all too frequently left to the unskilled attendants in doctors' surgeries, and is used indiscriminately for all types of pain. .The placing of plates is, of course, of prime importance, and it is here where skill and experience are required. Consider the application of diathermy to the hip-joint: by no means a straightforward proceeding. We are anxious to direct heat to the deep tissues surrounding this joint, at the same time preventing undue surface heating. I have tried various methods, and have arrived at the conclusion that one cannot dogmatise here. In most cases, I use a cuff electrode, strapped round the middle of the tigh, and a plate under the Sacrum of the opposite side. A pillow is placed under both knees, thus, generally, concentrating a deep heat in the hip-joint and sacro-iliac regions. The alternative is to use two plate electrodes, anteriorly and posteriorly, but here there often seems to be rather more surface heat, i.e. the skin becomes overheated before sufficient penetration has been achieved. The first method, however, appears to depend on slight flexion of the hips for its maximum /success, and in cases where pain makes this difficult, the latter method must be employed. I do not advocate the use of the coil. In my view, too much heat is lost when this method is used. The Shoulder-joint should be treated by the antero-posterior method, using plate electrodes. In my experience here, again, I have found the coil to produce more surface heat, i.e. heating of the skin, than can be comfortably tolerated if sufficient density is to be reached for the deeper structures. Brachial Neuritis, when treated by diathermy, requires a more general application. I have used the coil, the cuff and plate method, and the two pla:es, and I consider that the last is the best. The patient lies on the plinth with one plate under the scapula region. The other rests under the arm. which is supported by sandbags or a pillow. For five minutes the "Active" electrode rests under the forearm, then, with the elbow flexed, it is moved to the upper arm. In this way, a gradual heating effect is achieved. I would stress, however, that Brachial Neuritis is not always responsive to diathermy. I have found in many instances that it actually increases pain and aggravates the condition. It is in cases where reaction is variable with different individuals, that the judgment of a skilled physiotherapist is called for. The hand, when rigid as a result of gross adhesions, should be considered for diathermy.
Antero-Posterior application, with plates, is the method I choose, but I have seen' the coil utilised here, with some success. Another method is to raise the forearm on sandbags, with a plate under the flexor surface, while the fingers rest, lightly, on the other plate. This method of ten produces the most satisfactory heating of the distal joints.

A synovitised knee is pre-eminently suitable for diathermy, either by lateral application of plates or anteroposterior application. Tight strapping, however, should be avoided, as this often causes discomfort. Following manipulation of the ankle, diathermy is of great value. It not only increases circulation, and so assists the process of eliminating spasm of associated muscles, but it gives the patient a feeling of comfort which is most valuable. This feeling of comfort and ease, is conducive to exercising, probably the most necessary of all treatments in this instance.

I have, very briefly, discussed my subject, and I hope it might encourage other readers to do likewise. Only in this way, by sharing the experience we gain over vears of practice, can our patients derive the benefits, in full, which our profession can offer. Intelligent physiotherapy is an integral part of all surgery and medicine, but its abuse, either by ourselves or others, may create a situation where it may be regarded as "mere quackery" and be avoided in cases where it can be of the utmost value. This Journal provides one means of propaganda for the judicious use of the multiple physiotherapeutic agents, and it behoves all who have the interests of our profession at heart, to see to it that its pages contain material which will enhance our status and enrich all who have a just claim on the knowledge and skill which our training has provided for us.

\section{PETER \\ ROTHENBERG}

ELECTRICAL

AND INDUSTRIAL INSTRUMENTS

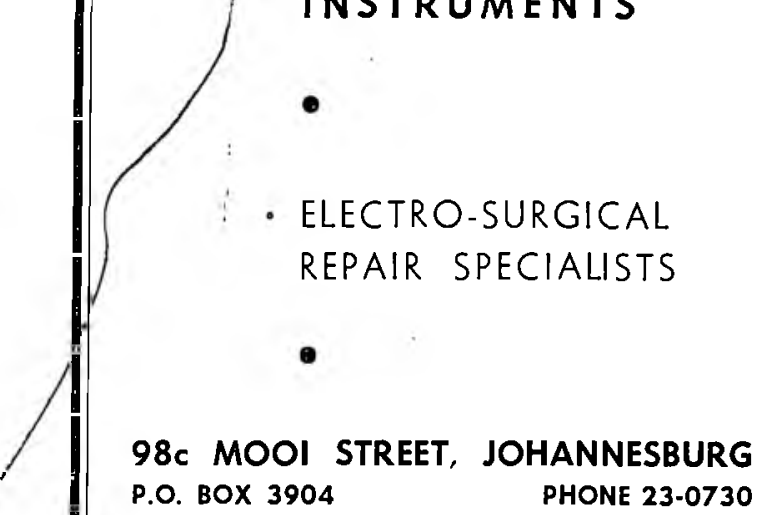

